\title{
Temporal precipitation trend analysis at the Langat River Basin, Selangor, Malaysia
}

\author{
Narges Palizdan ${ }^{1, *}$, Yashar Falamarzi ${ }^{1}$, Yuk Feng Huang $^{2}$, \\ Teang Shui LeE ${ }^{1}$ and Abdul Halim Ghazali ${ }^{1}$ \\ ${ }^{1}$ Department of Engineering, Universiti Putra Malaysia, 43400, UPM Serdang, Selangor, Malaysia. \\ ${ }^{2}$ Faculty of Engineering and Science, Universiti Tuanku Abdul Rahman, Kuala Lumpur, Malaysia. \\ *Corresponding author. e-mail: nargespalizdan87@gmail.com
}

The Langat River Basin provides fresh water for about 1.2 million people in the Langat and Klang valleys. Any change in the pattern of rainfall could affect the quantity of water in the basin. Studying the pattern of change in rainfall is crucial for managing the available water resources in the basin. Thus, in this study, for the first time, both parametric and non-parametric methods were employed to detect rainfall trend in the basin for the period 1982-2011. The trends were determined at 30 rainfall stations using the Mann-Kendall (MK) test, the Sen's slope estimator and the linear regression analysis. Lag-1 approach was utilized to test the serial correlation of the series. On the annual scale, it was found that most of the stations in the basin were characterized with insignificant trends. The significant trends were found only at the four stations, namely 44301, 44305, 44320 and 2719001. The results of the seasonal trend analysis showed that most of the stations during the northeast monsoon (NEM) and the inter monsoon 1 (INT1) seasons and half of the stations during the southwest monsoon (SWM) season experienced insignificant positive trends. To the contrary, for the inter monsoon 2 (INT2) season, majority of the stations showed negative trends. It was found that during the NEM season the station 44301, for the INT1 season stations 44301, 2719001 and 3118069 were established as having significant changes, while in the SWM season station 2917001 and during the INT2 season, the stations 2615131 and 44301 showed significant trends. It is worth mentioning that the maximum rainfall occurs in inter-monsoon seasons.

\section{Introduction}

Water is the most valuable material on the earth and fresh water is the reason for human survival, where precipitation is the main source. There is no doubt that precipitation is one significant climate factor that affects the environmental and natural processes. Precipitation is an essential component of the hydrological cycle and any change in its distribution may have a significant effect on the hydrosphere, biosphere and the society. According to Rana et al. (2011), information about the trends of rainfall is important because it is connected to the water-related issues of a region, its associated problems and for environment and water management purposes, etc. This information will be the most valuable to researchers studying climate change and its effects on water management. The detection of rainfall trends has been one of the main activities for both the hydrologist and the climatologist in pursuing climate change studies and research.

Many non-stationary features of climatic and hydrologic phenomena exist which have various periodic events at different periods ( $\mathrm{Wu}$ et al. 2009). The positive and negative trends in climate

Keywords. Langat River Basin; temporal precipitation; trend analysis.

J. Earth Syst. Sci. 124, No. 8, December 2015, pp. 1623-1638

(C) Indian Academy of Sciences 
and hydrological time series can be illustrated through changes in the factors such as precipitation, temperature, stream flow and water quality (Buishand and Kempen 1988; Andreo et al. 2006; Partal and Kahya 2006; Jiang et al. 2007; Kang and Lin 2007; Huang et al. 2008; Kumar et al. 2009). Trend analysis is useful for the understanding of these climatic and hydrological changes. Temperature and precipitation among other climate factors have the most interactive interface with climate change. Precipitation is exclusively important because changes in the pattern of precipitation could lead to floods or droughts in various areas.

Bonaccorso et al. (2005) determined the total annual and the maximum annual precipitation trends for different durations (1, 3, 6, 12 and $24 \mathrm{hr}$ ) between 1920 and 2000 in Sicily, Italy. Their results showed that the directions of annual precipitation trends were opposite to those of the maximum annual precipitation trends of some stations. They concluded that there is an opposite behaviour in annual maximum precipitation trends for short and long durations in the studied area (short durations showed increasing trends, while long durations showed decreasing trends). Cannarozzo et al. (2006) investigated the annual, seasonal and monthly precipitation trends and their spatial distributions in Sicily, Italy. The annual declining trend was observed at most of the stations and the region. In addition, winter and January had the most significant negative trends at 95\% confidence level for the seasonal and the monthly precipitations.

Modarres et al. (2007) investigated the trends of annual precipitation data series, number of rainy days per year and monthly precipitation time series in Iran. They concluded that there was no significant variation in precipitation over Iran. Cheung et al. (2008) studied the temporal dynamics of rainfall and its spatial distribution over Ethiopia for the duration of 1960-2002. The rainfall data was obtained from 134 stations in 13 watersheds. The changes and trends of seasonal and annual rainfall were computed at the gage, national and regional scales. The results showed that there was no significant change in annual rainfall in the watersheds. On the other hand, the results of seasonal rainfall trends showed significant downward trends in the watersheds located in the southwestern and central parts of Ethiopia. In addition, they concluded that the trends of each station are not necessarily reflected at the watershed or regional trends.

Basistha et al. (2009) determined the rainfall trends in the Indian Himalaya during the 20th century. They found that the most probable year of the shift in both the annual and the monsoon rainfall in the region was the year 1964. The results indicated an increasing trend from the beginning of the duration (1902) until 1964, followed by a decreasing trend from 1965 to 1980. De Lima et al. (2010) identified the monotonic and partial trends

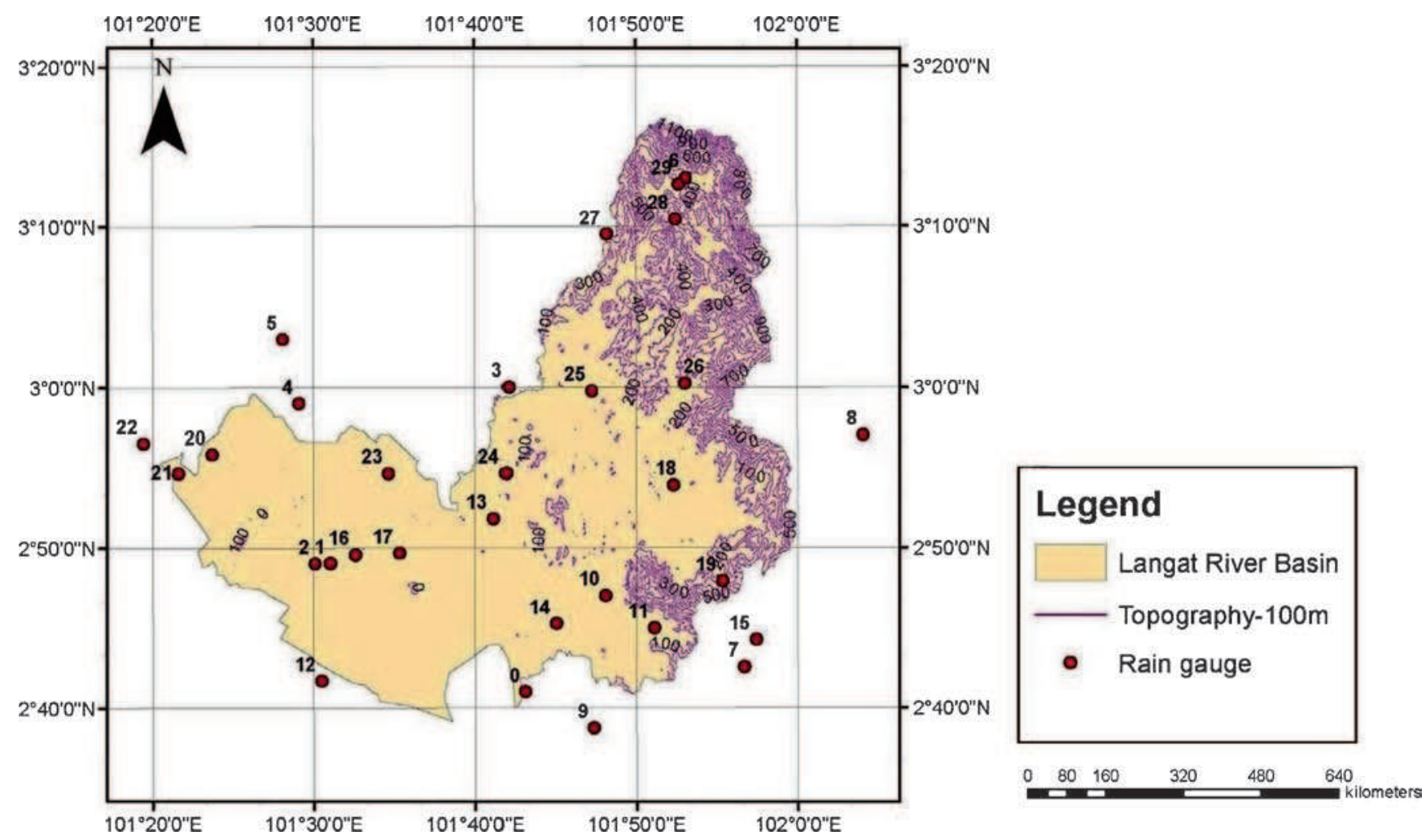

Figure 1. The Langat River Basin and the distribution of the selected stations, west Malaysia. 
in the annual and the monthly precipitation in Portugal. The results showed that when a monotonic linear model was applied there was no significant trend in the annual precipitation, while the partial trend analysis showed a sequence of alternating decreasing and increasing trends for both the annual and the monthly precipitation data series. Tabari and Talaee (2011) studied the annual and the seasonal precipitation trends over Iran for the period 1966-2005. An annual declining trend was observed at $60 \%$ of the stations. Only in seven stations the trends were significant at either the $95 \%$ or $99 \%$ confidence levels. From the spatial analysis of the annual precipitation trend, they found that the significant decreasing trends happen mostly in the northwest of Iran. The seasonal precipitation trend analysis showed that the trend in spring and winter was mostly negative.

Suhaila et al. (2010) investigated the trends of seasonal rainfall based on some indices including the total amount of rainfall, the frequency of wet days, the rainfall intensity and the extreme intensity. The trends were investigated for the period from 1975 to 2004 in peninsular Malaysia. Accordingly and rightly so, the results showed that the southwest monsoon had the greatest impact on the western part of the peninsular. In contrast, the northeast monsoon has the influence on the eastern part of the peninsular. During the southwest monsoon, although the downward trends were indicated in the total amount of rainfall in a season and the frequency of wet days, the rainfall intensity showed an increasing trend. On the other hand, during the northeast monsoon all of the three mentioned indices illustrated positive trends. In both seasons, the frequency of the wet days and the extreme intensity showed decreasing trends.

The climate of Malaysia is equatorial (hot and humid) throughout the year. It has been mentioned that the climate change is likely to have a significant impact on Malaysia, such as increasing sea levels, rainfall and flood risks. Therefore, it is necessary to determine the trends of climate variables to understand the effect of climate change on them. The Langat River Basin is one of the most important catchments in Malaysia. The reservoirs located within the Langat River Basin are the Semenyih dam and Langat dam that provide water for about 1.2 million people in the Langat and Klang valleys. Furthermore, there are eight watertreatment plants in the basin that provide clean water for the users. Besides providing fresh water, the reservoirs are also important to control floods. The Langat reservoir is also used to generate

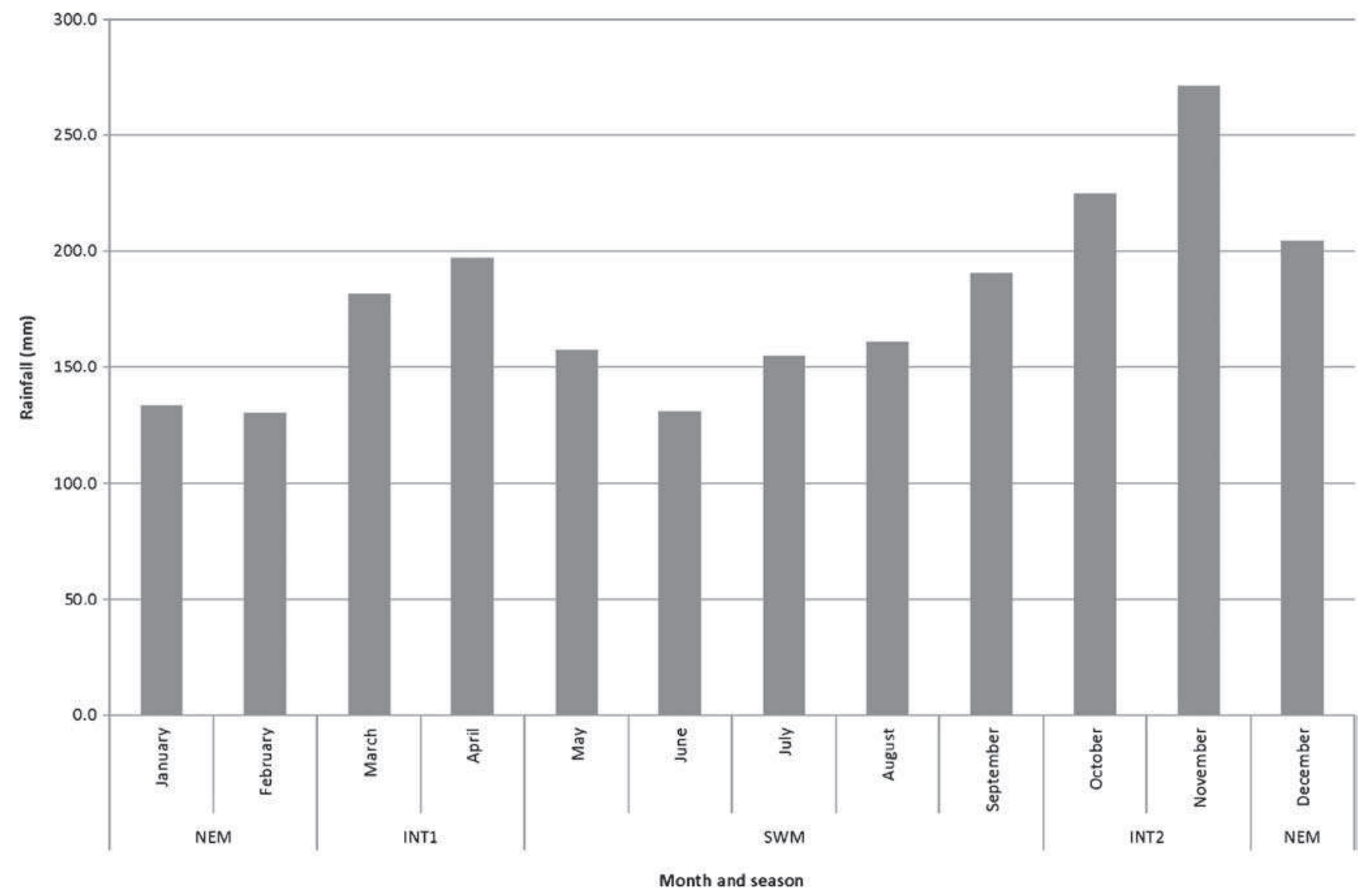

Figure 2. Graph of rainfall climatology of Langat River Basin during 1982-2011. 
hydroelectric power. Any change in the pattern of rainfall affects the quantity of water in the basin. Therefore, studying the trend of precipitation is essential for managing water resource in the study area.

Since in Malaysia, already a few studies such as Tangang et al. (2006) and Suhaila et al. (2010) have been performed to investigate the trends of climatic variables, in the present study, for the first time, the annual and seasonal precipitation trends at the Langat River Basin, Malaysia will be investigated using both parametric and nonparametric methods for the period 1982-2011. While it helps to certain extent with interpreting climate change responses, the usefulness of this trend analysis as well as the magnitude over time can be seen when water managers need to plan water recourses project and their related management well. One example is the management of water recourses in hydro-dams for electricity production and assessment of long time water availability.

\section{Materials and methods}

\subsection{Study area}

The study area is the Langat River Basin, Malaysia, which lies between $2^{\circ} 40^{\prime} 152^{\prime \prime}-3^{\circ} 16^{\prime} 15^{\prime \prime} \mathrm{N}$ and $101^{\circ} 19^{\prime} 20^{\prime \prime}-102^{\circ} 1^{\prime} 10^{\prime \prime} \mathrm{E}$ (figure 1). The whole area of the basin, which is about $2352 \mathrm{~km}^{2}$, is divided into three zones. The first zone is the mountainous zone of the northeast corner of the Hulu Langat district. The average height of the highland range is about 960 meters above the mean sea level with most of the mountainous region below $500 \mathrm{~m}$ from the mean sea level. The second zone is the hilly area with mild slopes. This zone stretches from the north to the east in the middle part of the Langat River Basin. The height of this area is generally below $100 \mathrm{~m}$. The third zone is relatively flat and it is located in the southwest of the watershed. This zone is bound by the hilly area to the north and the east and by the Straits of Malacca to the west. The climate of the Langat

Table 1. Coordinates, elevation, name and codes of the selected stations at the Langat River Basin, Malaysia.

\begin{tabular}{|c|c|c|c|c|c|}
\hline $\begin{array}{l}\text { Station } \\
\text { code }\end{array}$ & $\begin{array}{l}\text { Station ID } \\
\text { in the maps }\end{array}$ & Station name & Latitude & Longitude & $\begin{array}{c}\text { Elevation } \\
\text { above sea level }(\mathrm{m})\end{array}$ \\
\hline 44239 & 0 & Sepang estate & $2^{\circ} 41^{\prime} 00^{\prime \prime} \mathrm{N}$ & $101^{\circ} 43^{\prime} 00^{\prime \prime} \mathrm{E}$ & 29 \\
\hline 44255 & 1 & Pusat Pertanian Telok Datok & $2^{\circ} 49^{\prime} 02^{\prime \prime} \mathrm{N}$ & $101^{\circ} 30^{\prime} 57^{\prime \prime} \mathrm{E}$ & 6 \\
\hline 44256 & 2 & Banting oil palm research station & $2^{\circ} 49^{\prime} 00^{\prime \prime} \mathrm{N}$ & $101^{\circ} 30^{\prime} 00^{\prime \prime} \mathrm{E}$ & 5 \\
\hline 44301 & 3 & Pusat Pertanian Serdang & $3^{\circ} 00^{\prime} 00^{\prime \prime} \mathrm{N}$ & $101^{\circ} 42^{\prime} 00^{\prime \prime} \mathrm{E}$ & 44 \\
\hline 44304 & 4 & Mardi Klang & $2^{\circ} 59^{\prime} 00^{\prime \prime} \mathrm{N}$ & $101^{\circ} 29^{\prime} 00^{\prime \prime} \mathrm{E}$ & 3 \\
\hline 44305 & 5 & NEB Connaught bridge power station, Klang & $3^{\circ} 03^{\prime} 00^{\prime \prime} \mathrm{N}$ & $101^{\circ} 28^{\prime} 00^{\prime \prime} \mathrm{E}$ & 3.1 \\
\hline 44320 & 6 & Ampangan Ulu Langat & $3^{\circ} 13^{\prime} 00^{\prime \prime} \mathrm{N}$ & $101^{\circ} 53^{\prime} 00^{\prime \prime} \mathrm{E}$ & 233.3 \\
\hline 45241 & 7 & Hospital Seremban & $2^{\circ} 42^{\prime} 33^{\prime \prime} \mathrm{N}$ & $101^{\circ} 56^{\prime} 37^{\prime \prime} \mathrm{E}$ & 64.1 \\
\hline 45248 & 8 & Hospital Jelebu & $2^{\circ} 57^{\prime} 00^{\prime \prime} \mathrm{N}$ & $102^{\circ} 04^{\prime} 00^{\prime \prime} \mathrm{E}$ & 137.3 \\
\hline 45251 & 9 & Chemara research Tanah Merah & $2^{\circ} 38^{\prime} 44^{\prime \prime} \mathrm{N}$ & $101^{\circ} 47^{\prime} 15^{\prime \prime} \mathrm{E}$ & 5.4 \\
\hline 45253 & 10 & New Labu estate & $2^{\circ} 47^{\prime} 00^{\prime \prime} \mathrm{N}$ & $101^{\circ} 48^{\prime} 00^{\prime \prime} \mathrm{E}$ & 29 \\
\hline 45254 & 11 & Kirby estate & $2^{\circ} 45^{\prime} 00^{\prime \prime} \mathrm{N}$ & $101^{\circ} 51^{\prime} 00^{\prime \prime} \mathrm{E}$ & 57 \\
\hline 2615131 & 12 & Batu Untong & $2^{\circ} 41^{\prime} 40^{\prime \prime} \mathrm{N}$ & $101^{\circ} 30^{\prime} 25^{\prime \prime} \mathrm{E}$ & 3 \\
\hline 2616135 & 13 & Telok Merbau & $2^{\circ} 51^{\prime} 50^{\prime \prime} \mathrm{N}$ & $101^{\circ} 41^{\prime} 05^{\prime \prime} \mathrm{E}$ & 2 \\
\hline 2717114 & 14 & Bute & $2^{\circ} 45^{\prime} 15^{\prime \prime} \mathrm{N}$ & $101^{\circ} 44^{\prime} 55^{\prime \prime} \mathrm{E}$ & 3 \\
\hline 2719001 & 15 & Setor JPS. Sikamat & $2^{\circ} 44^{\prime} 15^{\prime \prime} \mathrm{N}$ & $101^{\circ} 57^{\prime} 20^{\prime \prime} \mathrm{E}$ & 30 \\
\hline 2815001 & 16 & Pejabat JPS. Sg. Manggis & $2^{\circ} 49^{\prime} 35^{\prime \prime} \mathrm{N}$ & $101^{\circ} 32^{\prime} 30^{\prime \prime} \mathrm{E}$ & 3 \\
\hline 2815115 & 17 & LDG. Brook Lands & $2^{\circ} 49^{\prime} 40^{\prime \prime} \mathrm{N}$ & $101^{\circ} 35^{\prime} 15^{\prime \prime} \mathrm{E}$ & 3 \\
\hline 2818110 & 18 & Sek. Men. Bandar Tasik Kesuma & $2^{\circ} 53^{\prime} 55^{\prime \prime} \mathrm{N}$ & $101^{\circ} 52^{\prime} 13^{\prime \prime} \mathrm{E}$ & 32 \\
\hline 2819002 & 19 & Jalan Sentul & $2^{\circ} 47^{\prime} 55^{\prime \prime} \mathrm{N}$ & $101^{\circ} 55^{\prime} 15^{\prime \prime} \mathrm{E}$ & 92 \\
\hline 2913001 & 20 & P/KWLN P/S Telok Gong & $2^{\circ} 55^{\prime} 50^{\prime \prime} \mathrm{N}$ & $101^{\circ} 23^{\prime} 35^{\prime \prime} \mathrm{E}$ & 3 \\
\hline 2913121 & 21 & LDG. West & $2^{\circ} 54^{\prime} 40^{\prime \prime} \mathrm{N}$ & $101^{\circ} 21^{\prime} 30^{\prime \prime} \mathrm{E}$ & 6 \\
\hline 2913122 & 22 & JPS. Pulau Lumut & $2^{\circ} 56^{\prime} 30^{\prime \prime} \mathrm{N}$ & $101^{\circ} 19^{\prime} 20^{\prime \prime} \mathrm{E}$ & 6 \\
\hline 2915116 & 23 & BKT. Cheeding & $2^{\circ} 54^{\prime} 40^{\prime \prime} \mathrm{N}$ & $101^{\circ} 34^{\prime} 35^{\prime \prime} \mathrm{E}$ & 4 \\
\hline 2916001 & 24 & Puncak Niaga Putrajaya & $2^{\circ} 54^{\prime} 40^{\prime \prime} \mathrm{N}$ & $101^{\circ} 41^{\prime} 50^{\prime \prime} \mathrm{E}$ & 38 \\
\hline 2917001 & 25 & RTM. Kajang & $2^{\circ} 59^{\prime} 46^{\prime \prime} \mathrm{N}$ & $101^{\circ} 47^{\prime} 09^{\prime \prime} \mathrm{E}$ & 39 \\
\hline 3018107 & 26 & LDG. Dominion & $3^{\circ} 00^{\prime} 13^{\prime \prime} \mathrm{N}$ & $101^{\circ} 52^{\prime} 55^{\prime \prime} \mathrm{E}$ & 61 \\
\hline 3118069 & 27 & Pemasokan Ampang & $3^{\circ} 09^{\prime} 30^{\prime \prime} \mathrm{N}$ & $101^{\circ} 48^{\prime} 05^{\prime \prime} \mathrm{E}$ & 88 \\
\hline 3118102 & 28 & Sek. Keb. Kg. Sg. Lui & $3^{\circ} 10^{\prime} 25^{\prime \prime} \mathrm{N}$ & $101^{\circ} 52^{\prime} 20^{\prime \prime} \mathrm{E}$ & 91 \\
\hline 3218101 & 29 & TNB. Ponsoon & $3^{\circ} 12^{\prime} 35^{\prime \prime} \mathrm{N}$ & $101^{\circ} 52^{\prime} 33^{\prime \prime} \mathrm{E}$ & 163 \\
\hline
\end{tabular}


River Basin is equatorial monsoon. In the area, high rainfall and high humidity occurs at various periods throughout the year. Similarly, high and uniform temperature is prevalent through the year. The climate over the Langat River Basin is divided into four seasons, the northeast monsoon (NEM) from December to February, the inter monsoon 1 (INT1) from March to April, the southwest monsoon (SWM) from May to September and the inter monsoon 2 (INT2) from October to November. The SWM, which blows across the Straits of Malacca, affects the weather of the basin more than the other seasons. The range of total annual rainfall is from 1900 to $3000 \mathrm{~mm}$ per year in the study area. Maximum rainfall occurs during the two inter monsoons, while minimum precipitation is prevalent during the two monsoon seasons. Figure 2 shows graph of the rainfall climatology of the basin during 1982-2011.

\subsection{Data}

Daily rainfall time series were obtained from the Department of Irrigation and Drainage (DID) (DID 2012), Malaysia and the Malaysian Meteorology Department (MMD) (MMD 2012) for 92 rainfall stations within and outside of the Langat River Basin. However, only 30 stations within and nearby the catchment have long time good data. The daily rainfall at each station was then aggregated to calculate the total seasonal and the total annual data series. Since at the time of conducting this study, the data of recent years was not provided by the responsible agencies, the common series' length of 30 years (1982-2011) for both the annual and the seasonal rainfall was determined. It should be noted that avoiding these $3-4$ years could not have a significant impact on the results of trend analysis, since trend is a gradual change in

Table 2. Results of the normality and homogeneity tests for annual and seasonal data series.

\begin{tabular}{|c|c|c|c|c|c|c|c|c|c|c|}
\hline \multirow{3}{*}{$\begin{array}{l}\text { Station } \\
\text { code }\end{array}$} & \multicolumn{5}{|c|}{ Shapiro-Wilk (normality) } & \multicolumn{5}{|c|}{ Homogeneity } \\
\hline & NEM & INT1 & SWM & INT2 & Annual & NEM & INT1 & SWM & INT2 & Annual \\
\hline & $1982-2011$ & 1982-2011 & $1982-2011$ & 1982-2011 & $1982-2011$ & $1982-2011$ & 1982-2011 & $1982-2011$ & $1982-2011$ & $1982-2011$ \\
\hline 44239 & 0.44 & 0.058 & 0.262 & 0.479 & 0.1 & 0.853 & 0.193 & 1 & 0.353 & 0.577 \\
\hline 44255 & 0.053 & 0.614 & 0.059 & 0.221 & 0.825 & 0.853 & 0.853 & 0.577 & 1 & 1 \\
\hline 44256 & $0.002 *$ & 0.911 & $0.002^{*}$ & 0.859 & $0.000 *$ & 1 & 0.853 & 1 & $0.041^{*}$ & 0.193 \\
\hline 44301 & 0.420 & 0.136 & 0.573 & $0.028 *$ & 0.667 & 1 & 0.577 & 0.094 & 0.853 & 0.853 \\
\hline 44304 & 0.46 & 0.077 & 0.113 & 0.185 & 0.896 & 0.353 & 0.577 & 0.094 & 0.094 & 0.353 \\
\hline 44305 & 0.161 & 0.353 & 0.061 & 0.724 & 0.681 & 0.853 & 0.193 & 0.353 & 0.577 & 0.577 \\
\hline 44320 & $0.012^{*}$ & $0.027^{*}$ & 0.86 & 0.366 & 0.155 & 0.577 & 0.577 & 1 & 0.353 & 0.577 \\
\hline 45241 & 0.718 & 0.780 & 0.859 & 0.347 & 0.457 & 0.577 & 0.094 & 0.353 & 0.577 & $0.005^{*}$ \\
\hline 45248 & 0.47 & 0.839 & 0.234 & $0.017^{*}$ & 0.28 & 0.353 & 0.353 & 0.193 & 0.094 & 1 \\
\hline 45251 & 0.768 & $0.016^{*}$ & 0.242 & 0.942 & 0.49 & 0.353 & 0.853 & 0.853 & 0.853 & 0.853 \\
\hline 45253 & 0.509 & 0.258 & 0.977 & 0.352 & 0.505 & 0.577 & 0.577 & 0.353 & 0.193 & 0.853 \\
\hline 45254 & $0.004^{*}$ & 0.269 & $0.004^{*}$ & 0.689 & 0.592 & 0.577 & 0.853 & 0.853 & 0.577 & 0.853 \\
\hline 2615131 & 0.292 & 0.392 & 0.608 & 0.07 & 0.532 & 0.853 & 0.353 & 0.577 & 0.353 & 0.577 \\
\hline 2616135 & 0.17 & $0.003^{*}$ & 0.117 & 0.668 & 0.125 & 0.853 & 0.853 & 0.353 & 0.577 & 0.853 \\
\hline 2717114 & 0.271 & 0.274 & $0.000^{*}$ & 0.067 & $0.000 *$ & 0.094 & 0.577 & 0.853 & 0.353 & 0.353 \\
\hline 2719001 & 0.675 & 0.293 & 0.765 & 0.305 & 0.034 & 1 & 0.094 & 0.577 & 0.853 & 0.193 \\
\hline 2815001 & 0.583 & 0.519 & 0.75 & 0.678 & 0.738 & 0.853 & $0.041^{*}$ & 0.853 & 1 & 0.193 \\
\hline 2815115 & 0.218 & 0.446 & 0.848 & 0.962 & 0.505 & 0.853 & 0.094 & 0.577 & 0.577 & 0.577 \\
\hline 2818110 & 0.103 & 0.149 & $0.014^{*}$ & 0.27 & 0.898 & 1 & 0.577 & 0.353 & 0.853 & 0.193 \\
\hline 2819002 & 0.781 & 0.27 & 0.438 & 0.162 & 0.228 & 0.353 & 0.577 & 0.353 & 1 & 0.353 \\
\hline 2913001 & 0.547 & 0.617 & 0.072 & 0.301 & 0.411 & 0.853 & 0.577 & 0.193 & 0.577 & 0.353 \\
\hline 2913121 & $0.044^{*}$ & 0.7 & 0.78 & 0.987 & 0.811 & 0.353 & 0.853 & 0.577 & 1 & 0.577 \\
\hline 2913122 & 0.107 & 0.139 & $0.009 *$ & $0.013^{*}$ & $0.003^{*}$ & $0.002^{*}$ & 0.353 & $0.005 *$ & 0.577 & $0.041^{*}$ \\
\hline 2915116 & 0.328 & 0.542 & 0.199 & 0.374 & 0.604 & 0.853 & $0.041 *$ & 1 & 0.853 & 0.193 \\
\hline 2916001 & 0.303 & 0.148 & 0.288 & 0.799 & 0.65 & 0.853 & 0.193 & 0.353 & 0.094 & 0.577 \\
\hline 2917001 & 0.536 & 0.254 & 0.937 & 0.056 & 0.219 & 0.577 & 0.193 & 0.853 & 0.832 & 1 \\
\hline 3018107 & 0.192 & 0.695 & 0.064 & $0.000^{*}$ & $0.000 *$ & 0.353 & 0.853 & 0.853 & 1 & 0.193 \\
\hline 3118069 & 0.319 & 0.151 & 0.834 & 0.093 & 0.101 & 0.577 & 0.353 & 0.853 & 0.577 & 0.353 \\
\hline 3118102 & 0.148 & 0.667 & 0.115 & 0.566 & 0.893 & 0.853 & 1 & $0.041 *$ & 0.193 & 0.353 \\
\hline 3218101 & 0.33 & 0.68 & 0.799 & 0.877 & $0.008^{*}$ & 0.853 & 0.577 & 0.853 & 1 & 0.09 \\
\hline
\end{tabular}

* Note: Data series is non-normal or inhomogenous at $95 \%$ level of significance. 
hydro-climatic data in a long period. The normality of the data at each station was investigated using the Shapiro-Wilk. According to Razali and Wah (2011), the Shapiro-Wilk test is the most powerful test for all distribution types and sample sizes. In this study, the Runs test, which is a non-parametric method, was utilized to test the randomness of data series. The non-parametric tests have the advantages of having less restrictive assumptions, simple calculations, applicable for both ordinal and nominal scales and there is no assumption about the distribution of data set (Bhardwaj 2009). The details of the stations and the results of the normality and the homogeneity tests are shown in tables 1 and 2, respectively.

\subsection{Parametric and non-parametric statistical tests}

Both parametric and non-parametric methods are commonly applied in order to determine trends
(Hamed and Ramachandra Rao 1998). The linear regression is an example of parametric tests. The Mann-Kendall (MK) test and the Sen's slope estimator can be mentioned as the examples of nonparametric methods. The statistical tests examine the null hypothesis $\left(H_{0}\right)$ that there is no trend against the alternative hypothesis $\left(H_{1}\right)$ that there is a trend. Although, parametric tests are more powerful in nature, they make more assumption than non-parametric methods (Corder and Foreman 2009). Parametric methods assume that the time series is normally distributed and independent. If a time series does not meet assumption of parametric tests then these methods can be very misleading (Kundzewicz and Robson 2004). Therefore, they are not often robust.

On the other hand, in non-parametric methods, there is no assumption about the distribution of data and these methods are appropriate for time series with censored and missing data, which are frequently observed in hydrological time series

Table 3. The result of lag-1 serial correlation test and the magnitude of r-lag1 for annual and seasonal data series at each station.

\begin{tabular}{|c|c|c|c|c|c|c|}
\hline \multirow[b]{2}{*}{$\begin{array}{l}\text { Station } \\
\text { code }\end{array}$} & \multirow[b]{2}{*}{$\begin{array}{l}\text { Station ID } \\
\text { in the maps }\end{array}$} & \multicolumn{5}{|c|}{ r-lag1 } \\
\hline & & $\begin{array}{l}\text { Annual } \\
\text { series }\end{array}$ & $\begin{array}{l}\text { NES } \\
\text { series }\end{array}$ & $\begin{array}{l}\text { INT1 } \\
\text { series }\end{array}$ & $\begin{array}{l}\text { SWM } \\
\text { series }\end{array}$ & $\begin{array}{l}\text { INT2 } \\
\text { series }\end{array}$ \\
\hline 44239 & 0 & 0.14 & -0.25 & 0.32 & -0.12 & -0.08 \\
\hline 44255 & 1 & 0.17 & -0.15 & 0.15 & -0.03 & -0.07 \\
\hline 44256 & 2 & 0.18 & -0.24 & 0.06 & 0.03 & 0.23 \\
\hline 44301 & 3 & 0.29 & 0.09 & 0.23 & -0.10 & 0.06 \\
\hline 44304 & 4 & -0.16 & -0.20 & 0.15 & -0.10 & -0.21 \\
\hline 44305 & 5 & 0.12 & -0.06 & 0.29 & 0.06 & -0.21 \\
\hline 44320 & 6 & 0.26 & -0.18 & 0.01 & 0.14 & 0.10 \\
\hline 45241 & 7 & 0.41 & -0.09 & 0.38 & 0.00 & -0.13 \\
\hline 45248 & 8 & 0.03 & 0.10 & 0.00 & 0.31 & -0.42 \\
\hline 45251 & 9 & 0.17 & -0.15 & 0.22 & -0.13 & -0.06 \\
\hline 45253 & 10 & -0.01 & -0.04 & -0.11 & -0.08 & -0.12 \\
\hline 45254 & 11 & 0.10 & -0.27 & 0.18 & -0.12 & -0.09 \\
\hline 2615131 & 12 & -0.02 & 0.05 & 0.05 & -0.07 & 0.17 \\
\hline 2616135 & 13 & 0.11 & -0.07 & 0.00 & 0.11 & 0.11 \\
\hline 2717114 & 14 & 0.58 & -0.26 & 0.36 & 0.20 & 0.14 \\
\hline 2719001 & 15 & 0.29 & 0.01 & 0.12 & 0.00 & -0.12 \\
\hline 2815001 & 16 & 0.24 & -0.29 & 0.42 & -0.21 & -0.05 \\
\hline 2815115 & 17 & 0.09 & -0.10 & 0.11 & -0.21 & 0.09 \\
\hline 2818110 & 18 & 0.31 & 0.19 & 0.06 & 0.28 & -0.11 \\
\hline 2819002 & 19 & 0.02 & -0.08 & -0.15 & 0.20 & -0.16 \\
\hline 2913001 & 20 & 0.26 & -0.07 & 0.25 & 0.20 & 0.16 \\
\hline 2913121 & 21 & 0.25 & 0.05 & 0.02 & 0.19 & -0.13 \\
\hline 2913122 & 22 & 0.66 & 0.57 & 0.02 & 0.60 & 0.53 \\
\hline 2915116 & 23 & 0.04 & 0.08 & 0.31 & 0.04 & -0.28 \\
\hline 2916001 & 24 & 0.33 & 0.02 & 0.36 & 0.07 & -0.41 \\
\hline 2917001 & 25 & 0.32 & 0.01 & 0.34 & -0.08 & -0.01 \\
\hline 3018107 & 26 & 0.52 & 0.31 & 0.25 & 0.32 & 0.33 \\
\hline 3118069 & 27 & 0.32 & 0.01 & 0.31 & 0.22 & -0.10 \\
\hline 3118102 & 28 & 0.23 & -0.11 & 0.00 & 0.25 & 0.09 \\
\hline 3218101 & 29 & 0.47 & 0.28 & 0.08 & 0.15 & 0.11 \\
\hline
\end{tabular}


(Miao et al. 2012), but they need that the data be independent. The hydrologic data are normally auto-correlated which violates the assumption of independent observation. They may also have seasonal fluctuations; therefore, values have not gotten constant distribution (Kundzewicz and Robson 2004).

In the present study, the linear regression method was utilized as the parametric method to detect rainfall trend. The MK and Sen's slope estimator tests were employed as the non-parametric tests.

\subsubsection{Linear regression analysis}

One of the parametric methods to detect the monotonic trend in the time series is the regression analysis method. The advantage of the regression analysis is that it jointly considers the information contained in the time series of counts or rates, rather than taking into account each point separately. Considering the time series as one unit, imposes stability, and consequently a narrower confidence band is computed in comparison with the confidence band calculated around each count or rate. Thus, any statistical test will be more powerful using the results of regression analysis. One type of the regression analysis methods is the least square linear regression method. It has been frequently employed to obtain the slope of hydrological and meteorological variables over time. In this test, the positive value of slope illustrates increasing trend and vice versa. One advantage of the linear regression method is that it gives both the significance and the magnitude of the trend (Tabari and Marofi 2010). The slope $b$ in the linear regression equation is an indicator to test the trend.

$$
\begin{gathered}
X=a+b t+\varepsilon \\
b=\frac{n \sum_{i=1}^{n} x_{i} t_{i}-\left(\sum_{i=1}^{n} x_{i}\right)\left(\sum_{i=1}^{n} t_{i}\right)}{n\left(\sum_{i=1}^{n} t_{i}^{2}\right)-\left(\sum_{i=1}^{n} t_{i}\right)^{2}}
\end{gathered}
$$

where $x_{i}$ is the value of climate factor measured at time $t_{i}$ and $n$ is the length of time series, $\varepsilon$ is the error term and $a$ is the intercept. While considering the time series, $x_{i}$ is fitted by the linear regression function (equation 1) and the standard error fulfills with the standard normal distribution, which has zero mean and unit standard deviation. The following equation calculates the sum of deviation square of variable $X\left(L_{X Y}\right)$ :

$$
\begin{aligned}
L_{X Y}= & \sum_{i=1}^{n}\left(x_{i}-\bar{x}\right)^{2}=\sum_{i=1}^{n}\left(x_{i}-\widehat{x}_{t}\right)^{2} \\
& +\sum_{i=1}^{n}\left(\widehat{x}_{i}-\bar{x}\right)^{2}=Q+U
\end{aligned}
$$

$$
U=\sum_{i=1}^{n}\left(\widehat{x}_{i}-\bar{x}\right)^{2}=b^{2} \sum_{i=1}^{n}\left(t_{i}-\bar{t}\right)^{2}
$$

and

$$
Q=L_{X Y}-U
$$

where $U$ is the regression sum of squares, which is the sum of deviation square between the return values and the measured mean values. $Q$ is the error sum of squares or residual sum of squares which is the sum of deviation squares between the measured values and the return values. The $F$ test is used to assess the significance of trend:

$$
F=\frac{U}{(Q /(n-2))} \sim F(1, n-2),
$$

\begin{tabular}{|c|c|c|c|c|}
\hline $\begin{array}{l}\text { Station } \\
\text { code }\end{array}$ & $\begin{array}{l}\text { Station ID } \\
\text { in the maps }\end{array}$ & $Z$ & $Q_{\text {med }}$ & $\begin{array}{c}b \\
(\mathrm{~mm} / \text { year})\end{array}$ \\
\hline 44239 & 0 & 0.18 & 0.98 & -0.47 \\
\hline 44255 & 1 & 1.93 & 16.41 & 12.26 \\
\hline 44256 & 2 & 0.30 & 1.69 & 11.61 \\
\hline 44301 & 3 & 2.75 & 22.08 & 21.33 \\
\hline 44304 & 4 & 1.86 & 17.14 & 14.53 \\
\hline 44305 & 5 & 2.50 & 26.61 & 25.50 \\
\hline 44320 & 6 & 2.21 & 13.48 & 15.79 \\
\hline 45241 & 7 & 1.93 & 21.81 & 22.90 \\
\hline 45248 & 8 & -0.18 & -1.17 & 0.92 \\
\hline 45251 & 9 & -0.32 & -1.44 & -0.45 \\
\hline 45253 & 10 & -0.46 & -5.42 & -4.42 \\
\hline 45254 & 11 & -0.18 & -2.70 & 1.04 \\
\hline 2615131 & 12 & -0.75 & -6.00 & -7.97 \\
\hline 2616135 & 13 & -1.43 & -9.77 & -11.89 \\
\hline 2717114 & 14 & -0.47 & -6.50 & -7.70 \\
\hline 2719001 & 15 & 2.46 & 21.22 & 21.95 \\
\hline 2815001 & 16 & 1.00 & 8.81 & 7.16 \\
\hline 2815115 & 17 & 1.50 & 10.26 & 9.57 \\
\hline 2818110 & 18 & 0.28 & 2.58 & 3.17 \\
\hline 2819002 & 19 & -0.46 & -2.88 & -4.81 \\
\hline 2913001 & 20 & -0.21 & -1.64 & -4.29 \\
\hline 2913121 & 21 & 0.14 & 0.65 & 0.05 \\
\hline 2913122 & 22 & -0.99 & -21.90 & -33.22 \\
\hline 2915116 & 23 & -1.18 & -9.67 & -6.65 \\
\hline 2916001 & 24 & -0.32 & 0.23 & -3.73 \\
\hline 2917001 & 25 & 0.88 & 10.36 & 14.36 \\
\hline 3018107 & 26 & 0.02 & 1.64 & 1.1 \\
\hline 3118069 & 27 & 0.81 & 9.57 & 14.69 \\
\hline 3118102 & 28 & 1.32 & 9.67 & 9.57 \\
\hline 3218101 & 29 & 1.14 & 11.00 & 15.93 \\
\hline
\end{tabular}

the rejection region for a given $\alpha$ confidence level is $w=\left\{F>F_{\alpha}(1, n-2)\right\}$.

Table 4. Values of $Z$ in $M K$ test, $Q_{\text {med }}$ in Sen's slope estimator and $b$ in linear regression analysis for annual data series (1982-2011). 


\subsubsection{The Mann-Kendall (MK) test}

The MK test is generally known as the Kendall's $\tau$ statistic. This test is a non-parametric rank based method and it has been widely used to test stationary against trend in hydrology and climatology time series (Zhang et al. 2000). The MK test could be applied for non-normally distributed data and time series, including outliers and nonlinear trends (Helsel and Hirsch 1992; Birsan et al. 2005). Furthermore, it is robust to the impact of inhomogeneous time series. In addition, this method is based on ranks of data, not actual value of the records. Therefore, the existence of outliers and missing data would not affect the results of MK test, significantly (Chaouche et al. 2010).

According to the test, the null hypothesis illustrates that seasonal data $\left(X_{1}, \ldots, X_{n}\right)$ is a sample of $n$ independent and identically distributed random variables (Hirsch et al. 1982). The alternative hypothesis $\mathrm{H}_{1}$ of a two-sided test is that the distributions of $X_{k}$ and $X_{j}$ are not identical for all $k$ and $j \leq n$ with $k \neq j$. To apply the MK test, first, the data are ordered according to the time $x_{1}, x_{2}, \ldots, x_{n}$, where $x_{i}$ is the measured value at time $i$. Then the sign of each $N$ possible differences $x_{j}-x_{k}$, where $j>k$ is recorded.

$$
\operatorname{sgn}\left(x_{j}-x_{k}\right)=\left\{\begin{array}{rll}
+1 & \text { if } & \left(x_{j}-x_{k}\right)>0 \\
0 & \text { if } & \left(x_{j}-x_{k}\right)=0 \\
-1 & \text { if } & \left(x_{j}-x_{k}\right)<0
\end{array}\right.
$$

then the $S$ statistic is calculated as follows:

$$
S=\sum_{i-1}^{n-1} \sum_{i=k+1}^{n} \operatorname{sgn}\left(x_{j}-x_{k}\right) .
$$

In the cases where the sample size is larger than 10 , the $S$ statistic is considered asymptotically normal, with $E(s)=0$ and variance is calculated as follows:

$$
\operatorname{var}(s)=\frac{\left[n(n-1)(2 n+5)-\sum_{i=0}^{m} t_{i}\left(t_{i}-1\right)\left(2 t_{i}+5\right)\right]}{18},
$$

where $n$ is the number of data points, $m$ is the number of tied groups (a tied group is a set of

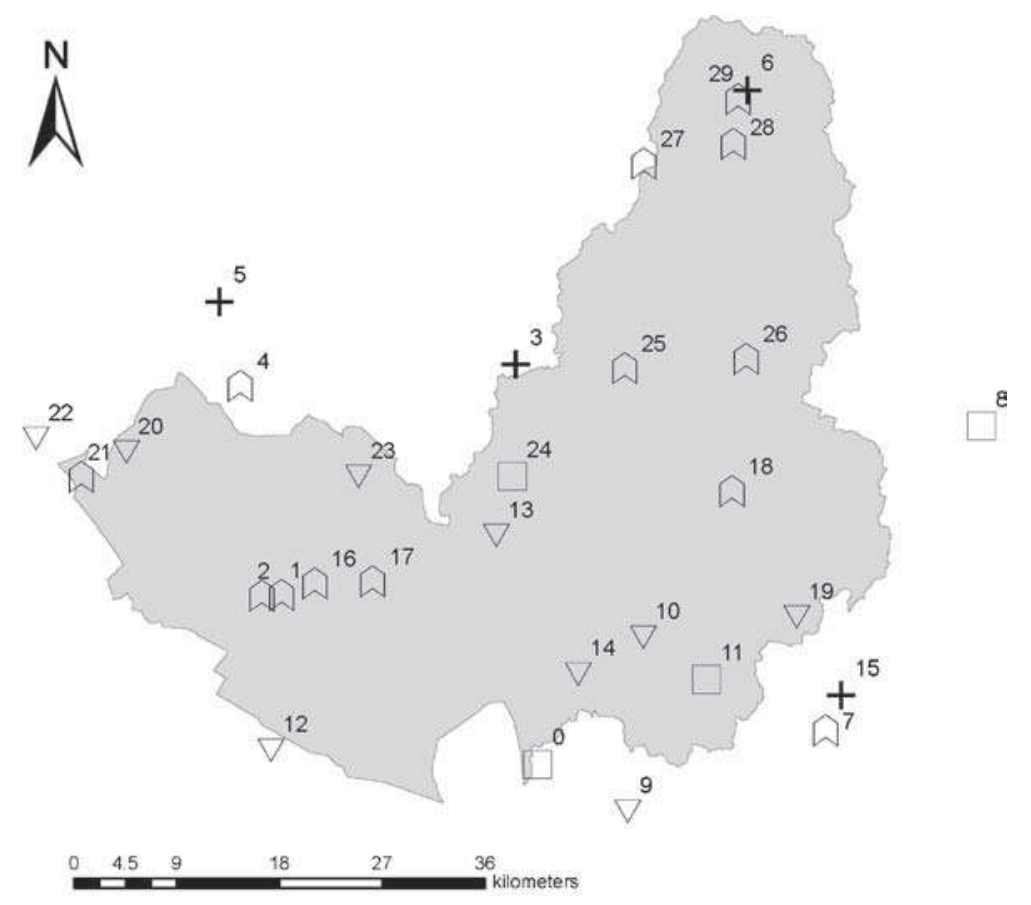

$$
\begin{aligned}
& \text { Legend } \\
& \text { Significance and direction of trend at annual scale } \\
& \begin{array}{cl}
\square & \text { Insignificant trend, Methods showed different directions } \\
\nabla & \text { Insignificant trend, Methods showed negative directions } \\
\square & \text { Insignificant trend, Methods showed positive directions } \\
+ & \text { Significant trend, Methods showed positive directions } \\
& \text { Langat River Basin }
\end{array}
\end{aligned}
$$

Figure 3. Significance and direction of trend at annual scale. 
sample data having the same value), and $t_{i}$ is the number of data points in the $i$ th group. Standard normal variable $Z$ is computed using the following equation:

$$
Z=\left\{\begin{array}{lll}
\frac{s-1}{\sqrt{\operatorname{var}(s)}} & \text { if } & s>0 \\
0 & \text { if } & s=0 . \\
\frac{s+1}{\sqrt{\operatorname{var}(s)}} & \text { if } & s<0
\end{array}\right.
$$

Thus, the hypothesis $H_{0}$ should be accepted where $|z| \leq z_{1}-\alpha / 2$ in a two-sided test for trend at $\alpha$ level of significance. The positive value of $Z$ shows an increasing trend and vice versa.

\subsubsection{Lag-1 serial correlation}

Existence of the autocorrelation in the time series affects the result of detection trends by the MK test (Hamed and Ramachandra Rao 1998; Serrano et al. 1999; Cunderlik and Burn 2004; Novotny and
Stefan 2007; Basistha et al. 2009). If there is a positive serial correlation in the time series, the probability of rejecting null hypothesis increases. The case is reverse for the negatively autocorrelated data series (Caloiero et al. 2011). Different methods have been developed to deal with the auto-correlated time series. Pre-whitening of the original time series prior applying the MannKendall test is recommended to remove the effect of serial correlation (Oguntunde et al. 2011).

One of the methods to perform pre-whitening is through the use of the lag-1 serial correlation coefficient. Caloiero et al. (2011) stated that lag-1 serial correlation method has been recommended as the most adapt approach to perform pre-whitening analysis. The lag-1 serial correlation coefficient $\left(r_{1}\right)$ can be calculated by the following equation:

$$
r_{1}=\frac{\frac{1}{n-1} \sum_{t=1}^{n-1}\left[X_{t}-E\left(X_{t}\right)\right]\left[X_{t+1}-E\left(X_{t}\right)\right]}{\frac{1}{n} \sum_{t=1}^{n}\left[X_{t}-E\left(X_{t}\right)\right]^{2}}
$$

Table 5. Values of $Z$ in $M K$ test, $Q_{\text {med }}$ in Sen's slope estimator and b in linear regression analysis for seasonal (197r-2011)

\begin{tabular}{|c|c|c|c|c|c|c|c|}
\hline \multirow{2}{*}{$\begin{array}{l}\text { Station } \\
\text { code }\end{array}$} & \multirow{2}{*}{$\begin{array}{l}\text { Station ID } \\
\text { in the maps }\end{array}$} & \multicolumn{3}{|c|}{ NEM } & \multicolumn{3}{|c|}{ INT1 } \\
\hline & & $Z$ & $Q_{\text {med }}$ & $b(\mathrm{~mm} /$ year $)$ & $Z$ & $Q_{\text {med }}$ & $b(\mathrm{~mm} /$ year $)$ \\
\hline 44239 & 0 & -0.18 & -0.56 & -0.37 & -0.43 & -0.80 & 0.96 \\
\hline 44255 & 1 & 0.64 & 2.02 & 1.50 & 1.11 & 3.03 & 2.87 \\
\hline 44256 & 2 & 0.00 & 0.04 & 0.34 & 0.77 & 1.77 & 1.63 \\
\hline 44301 & 3 & 2.28 & 8.64 & 8.00 & 2.39 & 7.34 & 7.15 \\
\hline 44304 & 4 & 0.82 & 3.60 & 2.57 & 1.82 & 5.22 & 5.19 \\
\hline 44305 & 5 & 1.78 & 7.70 & 9.98 & 1.78 & 6.20 & 6.98 \\
\hline 44320 & 6 & 0.04 & 0.13 & 1.02 & 1.21 & 3.11 & 4.30 \\
\hline 45241 & 7 & 1.32 & 6.51 & 5.91 & 1.41 & 7.52 & 7.83 \\
\hline 45248 & 8 & 0.18 & 0.82 & 1.21 & 0.68 & 2.37 & 2.45 \\
\hline 45251 & 9 & -0.04 & -0.09 & -0.13 & -0.36 & -0.73 & 0.39 \\
\hline 45253 & 10 & 1.57 & 5.50 & 4.35 & -0.57 & -1.85 & -0.07 \\
\hline 45254 & 11 & -0.43 & -1.94 & -0.80 & 0.96 & 3.08 & 2.64 \\
\hline 2615131 & 12 & 0.71 & 1.61 & 2.04 & 1.43 & 2.77 & 3.15 \\
\hline 2616135 & 13 & -0.50 & -1.48 & -0.99 & 0.04 & 0.00 & 1.00 \\
\hline 2717114 & 14 & 0.29 & 1.38 & 0.62 & 0.24 & 0.58 & 0.70 \\
\hline 2719001 & 15 & 0.93 & 3.58 & 3.71 & 2.82 & 10.22 & 7.75 \\
\hline 2815001 & 16 & 0.84 & 2.06 & 0.98 & 0.24 & 1.93 & 0.64 \\
\hline 2815115 & 17 & 0.16 & 0.20 & -0.76 & 0.61 & 1.75 & 1.03 \\
\hline 2818110 & 18 & -1.09 & -3.44 & -2.72 & 1.03 & 3.88 & 2.87 \\
\hline 2819002 & 19 & 0.16 & 0.59 & 0.81 & 0.68 & 2.31 & 2.09 \\
\hline 2913001 & 20 & -0.25 & -1.23 & -0.97 & 0.46 & 1.51 & 2.28 \\
\hline 2913121 & 21 & -0.41 & -1.00 & -1.18 & 0.77 & 1.48 & 1.29 \\
\hline 2913122 & 22 & -1.41 & -6.23 & -6.94 & -0.05 & -0.10 & -0.63 \\
\hline 2915116 & 23 & -1.25 & -3.00 & -3.73 & 0.07 & 0.68 & -0.04 \\
\hline 2916001 & 24 & -1.07 & -4.63 & -3.79 & 0.84 & 2.04 & 1.58 \\
\hline 2917001 & 25 & 1.32 & 6.60 & 6.84 & 0.66 & 4.75 & 3.79 \\
\hline 3018107 & 26 & -0.54 & -1.07 & -0.64 & 0.68 & 1.77 & 2.74 \\
\hline 3118069 & 27 & 0.32 & 0.89 & 0.70 & 2.00 & 8.00 & 8.70 \\
\hline 3118102 & 28 & -0.14 & -0.25 & 0.04 & 1.96 & 7.26 & 7.20 \\
\hline 3218101 & 29 & 1.11 & 6.39 & 5.92 & 1.46 & 6.31 & 6.46 \\
\hline
\end{tabular}
data series in NEM and INT1 seasons. 
where $X_{t}$ is the sample point at time $t$ and $E\left(X_{t}\right)$ is the mean of sample data. The significance of $r_{1}$ is assessed at relevant $\alpha$ level of significance for the two-tailed test. If $r_{1}$ is significant, then the pre-whitening operation is done as follows:

$$
Y_{t}=X_{t}-r_{1} X_{t-1},
$$

where $Y$ is the pre-whitened time series.

\subsubsection{Sen's slope estimator}

When a linear trend exists in a time series, a simple non-parametric method, Sen's slope estimator can be applied in order to compute the change per unit time (slope) in the time series. Sen's slope estimator has advantages of simplicity, capability of handling non-normal and missing data distributions, and robustness to the impacts of outliers and gross data errors (Olofintoye et al. 2012). In this method, when there are $N$ pairs of data, the slope is estimated as follows:

$$
Q_{i}=\frac{X_{j}-X_{K}}{j-K} \text { for } i=1, \ldots, N,
$$

where $X_{j}$ and $X_{k}$ are the data values at time $j$ and $K(j>K)$, respectively. The median of these $N$ values of $Q_{i}$ is Sen's estimator of slope.

If $N$ is odd, then Sen's estimator is computed by the following equation:

$$
Q_{\text {med }}=\left[Q_{(N+1) / 2}\right],
$$

if $N$ is even, then Sen's estimator is computed as follows:

$$
Q_{\mathrm{med}}=\frac{1}{2}\left[Q_{N / 2}+Q_{(N+2) / 2}\right]
$$

then the confidence interval is computed as follows:

$$
C_{\alpha}=Z_{1-(\alpha / 2)} \sqrt{\operatorname{var}(S)},
$$

\begin{tabular}{|c|c|c|c|c|c|c|c|}
\hline \multirow{2}{*}{$\begin{array}{l}\text { Station } \\
\text { code }\end{array}$} & \multirow{2}{*}{$\begin{array}{l}\text { Station ID } \\
\text { in the maps }\end{array}$} & \multicolumn{3}{|c|}{ SWM } & \multicolumn{3}{|c|}{ INT2 } \\
\hline & & $Z$ & $Q_{\text {med }}$ & $b(\mathrm{~mm} /$ year $)$ & $Z$ & $Q_{\text {med }}$ & $b(\mathrm{~mm} /$ year $)$ \\
\hline 44239 & 0 & -0.37 & -0.96 & -0.34 & 0.14 & 0.25 & 0.02 \\
\hline 44255 & 1 & 1.25 & 5.84 & 4.66 & 0.55 & 1.08 & 2.42 \\
\hline 44256 & 2 & 0.04 & 0.35 & 4.59 & -0.07 & -0.61 & 0.85 \\
\hline 44301 & 3 & 0.14 & 0.90 & 0.28 & 2.18 & 4.49 & 6.10 \\
\hline 44304 & 4 & 0.00 & -0.08 & 1.03 & 1.18 & 5.11 & 5.31 \\
\hline 44305 & 5 & 0.79 & 3.04 & 2.15 & 1.18 & 5.11 & 5.31 \\
\hline 44320 & 6 & 1.57 & 8.33 & 9.22 & 0.68 & 1.32 & 1.29 \\
\hline 45241 & 7 & 1.07 & 3.60 & 5.12 & 1.68 & 4.47 & 5.11 \\
\hline 45248 & 8 & -0.51 & -3.20 & -3.35 & -0.02 & -0.94 & -0.07 \\
\hline 45251 & 9 & 0.68 & 1.89 & 1.74 & -1.03 & -2.32 & -1.59 \\
\hline 45253 & 10 & -1.86 & -8.71 & -7.55 & -0.18 & -0.72 & -0.24 \\
\hline 45254 & 11 & -1.68 & -5.15 & -0.85 & 0.50 & 1.75 & 1.19 \\
\hline 2615131 & 12 & -0.82 & -5.13 & -6.05 & -2.50 & -5.70 & -6.42 \\
\hline 2616135 & 13 & -1.71 & -6.88 & -7.85 & -1.36 & -4.44 & -3.91 \\
\hline 2717114 & 14 & -0.86 & -3.65 & -4.43 & -0.82 & -3.69 & -3.29 \\
\hline 2719001 & 15 & 2.53 & 9.33 & 9.60 & 0.32 & 1.38 & 0.91 \\
\hline 2815001 & 16 & 1.02 & 4.11 & 2.92 & 0.50 & 1.55 & 1.98 \\
\hline 2815115 & 17 & 1.53 & 5.70 & 5.96 & 1.21 & 3.26 & 3.15 \\
\hline 2818110 & 18 & -0.11 & -0.55 & 1.33 & 0.62 & 0.85 & 1.29 \\
\hline 2819002 & 19 & -0.66 & -3.00 & -2.27 & -1.52 & -4.93 & -5.59 \\
\hline 2913001 & 20 & -0.61 & -1.92 & -2.90 & -1.39 & -3.18 & -3.18 \\
\hline 2913121 & 21 & 0.64 & 3.25 & 1.63 & -0.87 & -3.07 & -1.57 \\
\hline 2913122 & 22 & -0.77 & -12.05 & -17.05 & -1.11 & -5.24 & -8.04 \\
\hline 2915116 & 23 & -0.71 & -2.56 & -2.05 & 0.05 & 0.25 & -0.43 \\
\hline 2916001 & 24 & -0.29 & -1.16 & -1.37 & -0.13 & 0.18 & -0.62 \\
\hline 2917001 & 25 & 0.25 & 1.00 & 2.05 & 0.27 & 1.20 & 1.07 \\
\hline 3018107 & 26 & 0.73 & 3.40 & 2.96 & -0.09 & -1.40 & -2.76 \\
\hline 3118069 & 27 & 1.18 & 3.30 & 4.80 & -0.16 & -0.36 & -0.73 \\
\hline 3118102 & 28 & 0.87 & 3.18 & 1.62 & -0.14 & -0.47 & -1.04 \\
\hline 3218101 & 29 & 0.11 & 1.23 & -0.28 & 0.54 & 2.17 & 2.72 \\
\hline
\end{tabular}

Table 6. Values of $Z$ in $M K$ test, $Q_{m e d}$ in Sen's slope estimator and b in linear regression analysis for seasonal (1977-2011) data series in $S W M$ and INT2 seasons. 
where

$\operatorname{var}(S)=\frac{\left[n(n-1)(2 n+5)-\sum_{i=1}^{m} t_{i}\left(t_{i}-1\right)\left(2 t_{i}+5\right)\right]}{18}$,

in which $n$ refers to the number of sample data. $Z_{1-(\alpha / 2)}$ is obtained from the standard normal distribution. $M_{1}$ and $M_{2}$ can be found with the two accompanying equations: $M_{1}=\left(N-C_{\alpha}\right) / 2$ and $M_{2}=\left(N+C_{\alpha}\right) / 2\left(N\right.$ refers to the number of $\left.Q_{i} \mathrm{~s}\right)$. $Q_{\min }$ and $Q_{\max }$ are the lower and upper limits of the confidence interval, respectively. They are $M_{1}$ th and $\left(M_{2}+1\right)$ th of $N$ ascending-ordered slope estimator, $Q_{i}$, respectively. If $M_{1}$ is not a whole number, the lower limit is interpolated and if $M_{2}$ is not a whole number, the upper limit is interpolated (Tabari and Talaee 2011).

\subsection{Application of the methodology}

Annual and seasonal precipitation trends were identified using both the parametric and the non-parametric methods. The Mann-Kendall test and the Sen's slope estimator were employed as the non-parametric tests, while the linear regression method was applied as the parametric test. The 95\% confidence level was chosen to assess the significance of trends. As far as the Mann-Kendall method is sensitive to the serial correlation, this criterion was examined with the lag-1 approach, prior applying the MK test. Whenever the r-lag1 value was significant at $95 \%$ confidence level, the data series was pre-whitened. As shown in table 3, only a few data series have the significant r-lag1 value. It should be noted that in this study, the stations which showed significant trend using all the three methods were considered as the stations with significant trend.

\section{Results and discussion}

\subsection{Annual trends}

Table 4 shows the results of annual precipitation trends and their magnitudes (mm/year). Both
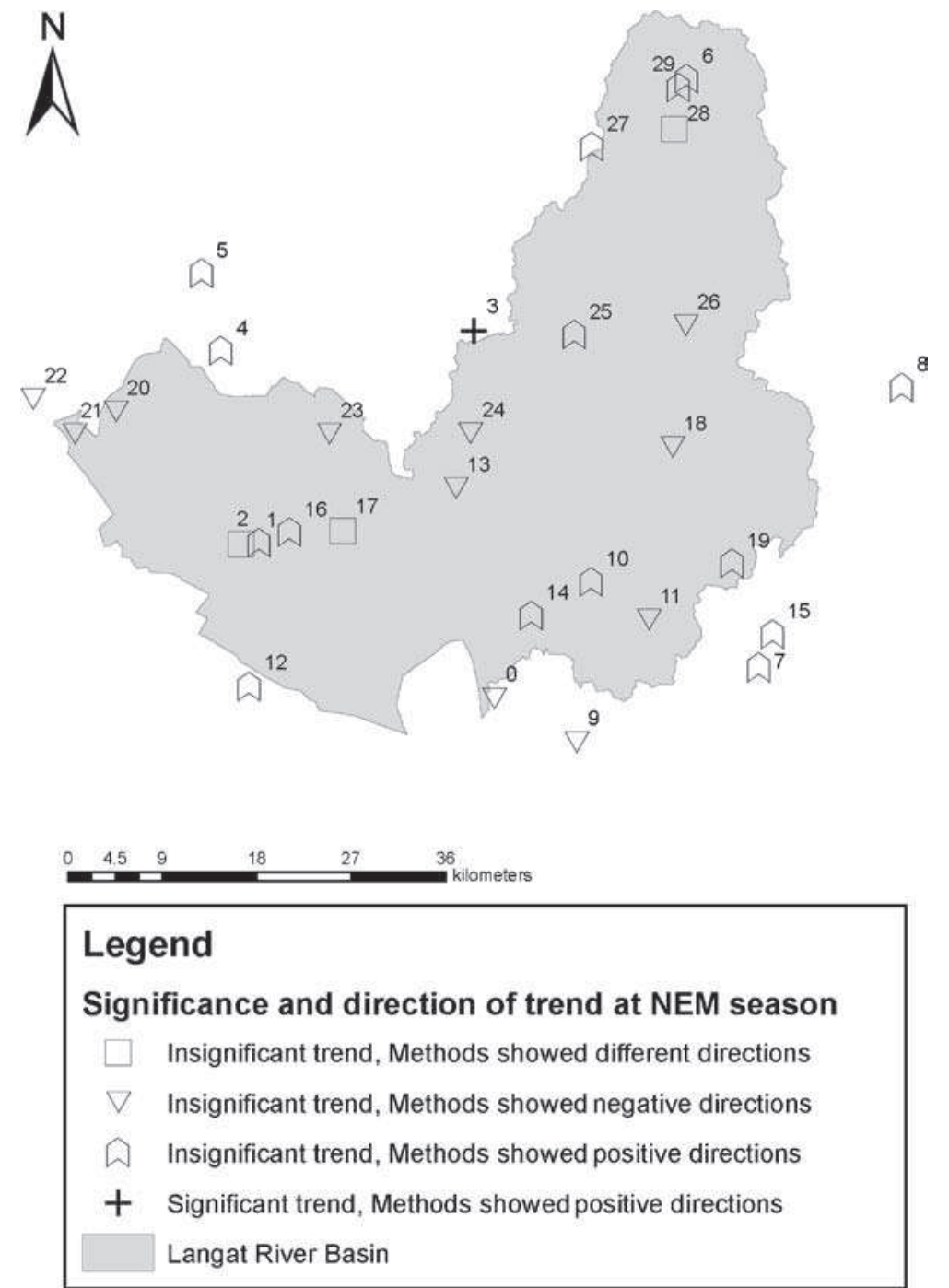

Figure 4. Significance and direction of trend at NEM season. 
increasing and decreasing trends are observed in the annual series. However, most of the trends are insignificant at $95 \%$ confidence level. The results of annual trend analysis with the linear regression method are generally similar to those obtained with the non-parametric approach (Sen's slope estimator). It should be mentioned that the Sen's slope estimator and the linear regression analysis do not essentially give the same answer because they are different methods. However, the highest difference in results of methods was seen in the station 2913122, which has non-normal distributed and inhomogeneous data. It should be noted that the Mann-Kendall test shows only the direction of trends, while the linear regression analysis and Sen's slope estimator show both the direction and the magnitude of trends.

The results of the MK test on the annual scale show that four out of 30 stations had significant trends. Utilizing Sen's slope estimator and linear regression methods, significant trends can be illustrated at 5 and 6 stations, respectively. However, only four stations (44301, 44305, 44320 and 2719001) revealed significant trends applying all three methods. All of the significant trends at $95 \%$ confidence level were positive. This shows that the amount of annual rainfall was increased during 1982-2011. The magnitude of the significant increasing trends varied between $15.79(\mathrm{~mm} /$ year $)$ at the station 44320 and 25.50 (mm/year) at the station 44305. The distribution of the annual precipitation trend revealed that the significant upward trends occurred in the north and the southeast of the basin. Adversely, insignificant trend was determined in different parts of the basin. The north and southeast of the basin is relatively a hilly area, where the magnitude of rain and its fluctuations could be higher than other parts of the basin. According to table 4, it is clear that 17 stations

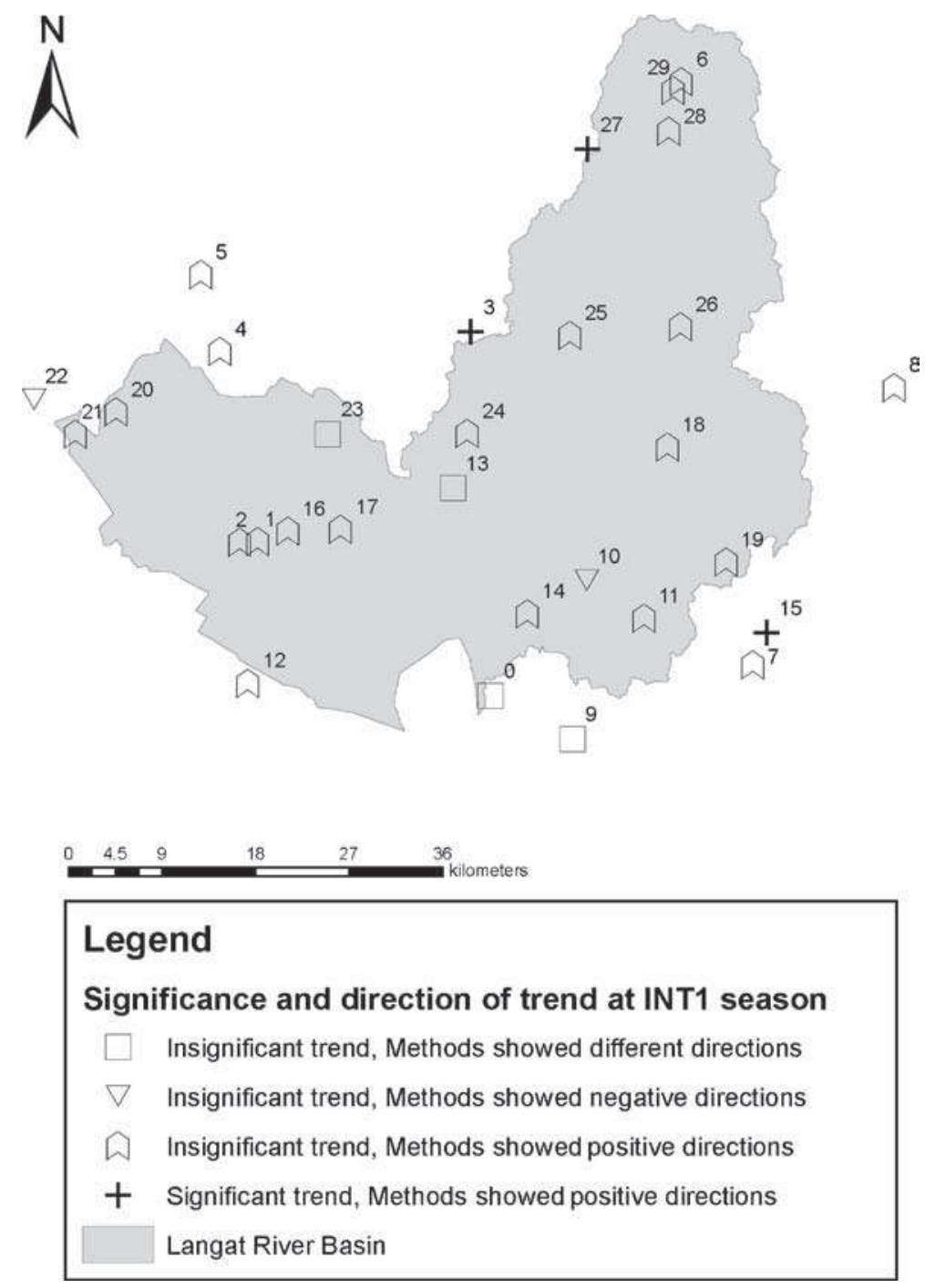

Figure 5. Significance and direction of trend at INT1 season. 
(57\%) have positive trends using both the non-parametric and the parametric methods. Therefore, it could be concluded that most of the stations in the Langat River Basin were characterized by positive annual precipitation trends during the study period (figure 3 ). If this positive trend continues in future, it is expected to have reliable source of water for the catchment at annual scale. However, other affecting factors on water resources such as the rate of urbanization and population increase rate should also be considered in order to plan water resources management strategies for the future.

\subsection{Seasonal trends}

From the seasonal outlook, the results of the parametric test are generally similar to the results of the non-parametric methods (tables 5 and 6). The reason for this similarity is that the majority of the stations have normally distributed and homogenous data. However, at the stations 44256 and 2913122 in the SWM season, the results of the Sen's slope estimator are significantly different from the results of the parametric method. Looking at table 2, it is clear that both the stations have a non-normally distributed time series in this season which could have the impact on the results of the linear regression method. It can be seen clearly from table 5 that the majority of trends in the NEM season data series were positive applying all three methods, accounting for about $57 \%$ of the stations. These positive trends are distributed all over the basin. The linear regression analysis revealed significant trends at the stations 44301 and 44305. However, only the station 44301 showed a positive significant trend applying all the three methods (figure 4 ). In the INT1 season, it can be observed that $83 \%$ of the stations indicated upward trends utilizing all the three approaches. However, the application of all the three methods revealed significant positive trends
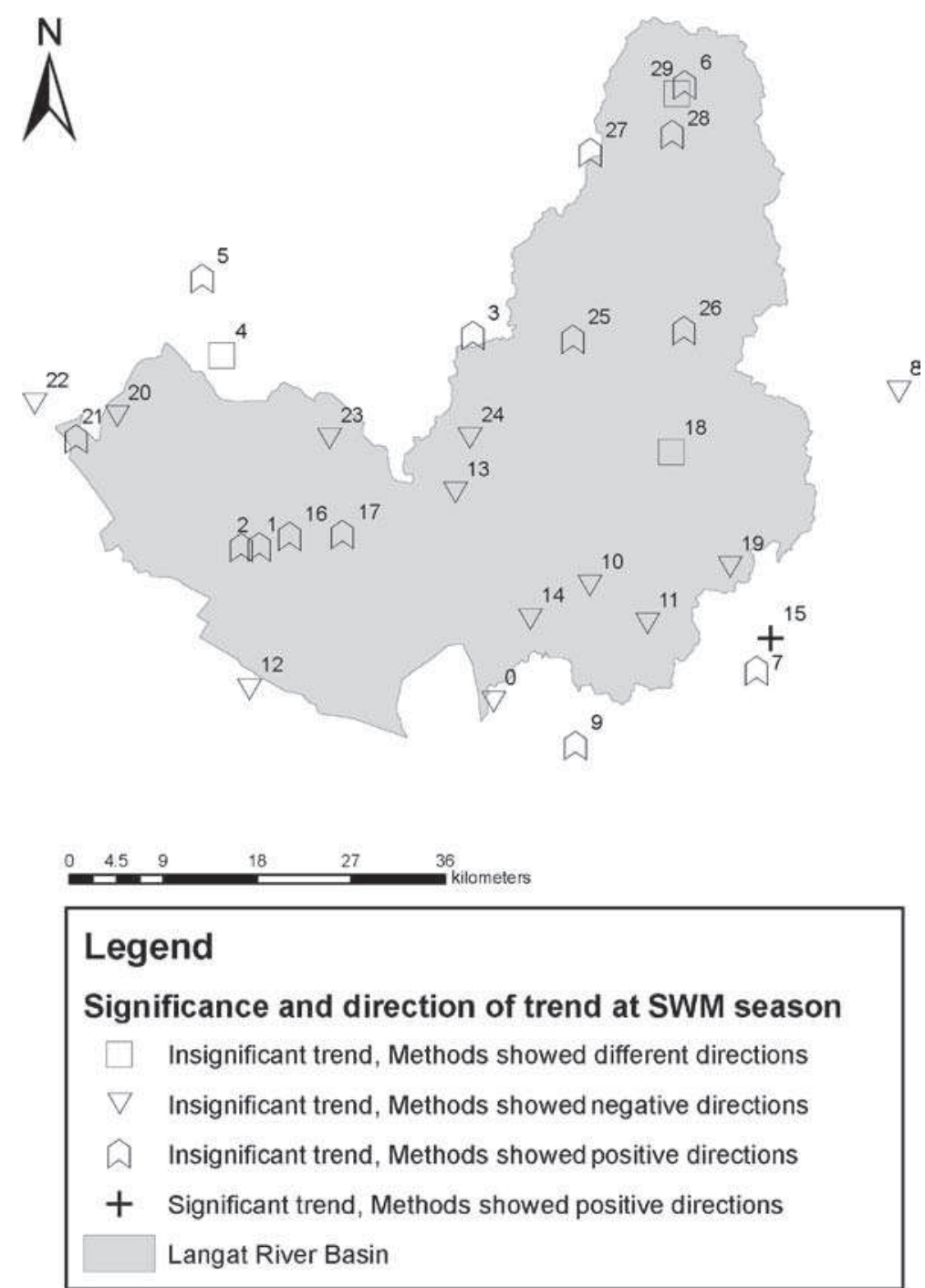

Figure 6. Significance and direction of trend at SWM season. 

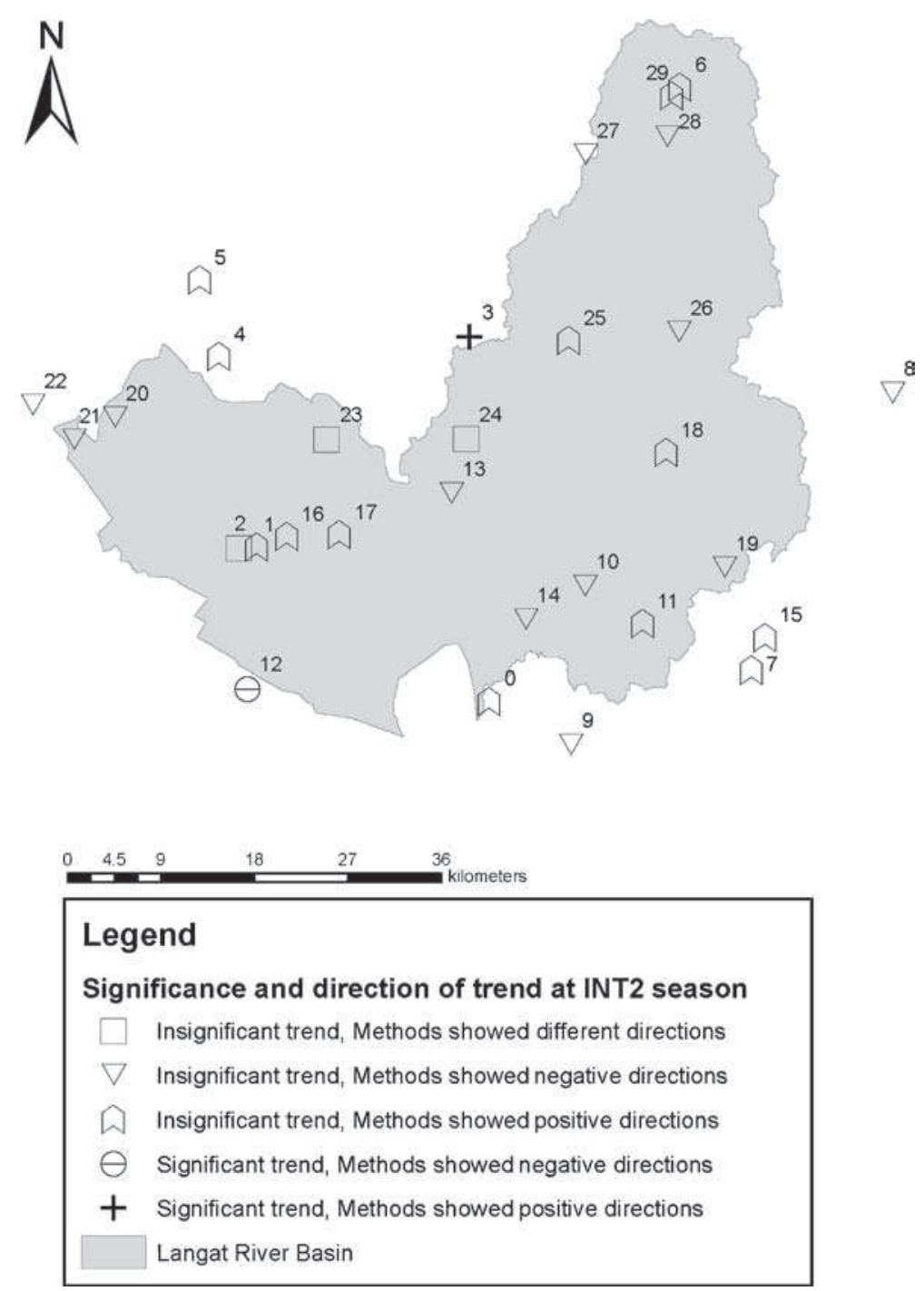

Figure 7. Significance and direction of trend at INT2 season.

only at the stations 44301, 2719001 and 3118069 with the slopes of $7.15,7.75$ and $8.7 \mathrm{~mm} /$ year, respectively (figure 5). Half of the stations in the SWM season experienced positive trends utilizing all the three methods. Applying the linear regression analysis showed significant downward trends at the stations $45253((-) 7.55 \mathrm{~mm} /$ year $)$ and $2913122((-) 17.05 \mathrm{~mm} /$ year $)$. However, only the station 2719001 showed a significant increasing trend using all the three methods (figure 6). To the contrary, in the INT2 season, $53 \%$ of the stations illustrated negative trends. However, applying all the three tests illustrated the significant negative and positive trends at the stations 2615131 and 44301, respectively (figure 7). It is obvious that utilizing three methods indicated significant negative trends only in the INT2 season time series, while increasing trends exist in all other seasons. The reason for this may be that INT2 season is before the NEM which has a weaker impact on the climate of the basin than the SWM.
Accordingly, as can be seen in tables 5 and 6 , the number of stations with the significant positive trend in INT1 season (3 stations) is more than other seasons. In addition, two of these three stations also showed significant positive trend in the annual scale. In addition, 19 stations (63\%) have the same trend direction in both the annual and the INT1 season scales. Generally, these findings reveal that the INT1 season precipitation series has a greater contribution to the annual precipitation in the Langat River Basin. It is in agreement with generally occurring localized thunder storms with high intensities during the INT1 period, typically, the late afternoon thunderstorms.

\section{Conclusions}

Rainfall data series of 30 stations over the Langat River Basin in the state of Selangor, Malaysia, were 
studied in order to investigate the precipitation trend in the period 1982-2011. The Mann-Kendall test, the Sen's slope estimator and the linear regression analysis were utilized to detect trends. The significance of the trends was assessed at $95 \%$ confidence level. The findings of the trend analysis at both the annual and the seasonal scales showed that the results of the non-parametric methods are almost similar to the results of the parametric test. However, applying non-parametric methods on the stations 44256 and 2913122 in the annual and the SWM season produced different results compared with the results of the parametric test. Both the stations have non-normally distributed time series at both the annual and the SWM season. This finding proves the effect of non-normal distributed data series on the result of parametric tests.

On the annual basis, it was observed that approximately $57 \%$ of the stations showed positive trend. However, the stations 44301, 44305, 44320 and 2719001 are the only stations that illustrated significant upward trends evaluated using all the three methods. On the seasonal scale, the majority of the stations showed insignificant trends. During the NEM and INT1 seasons, most of the stations $(57 \%$ of the stations in the NEM season and $83 \%$ of the stations in the INT1 season) experienced positive trends. The significant upward trends were observed at the station 44301 (8 $\mathrm{mm} /$ year) in the NEM season, stations 44301 (7.15 mm/year), 2719001 (7.75 mm/year) and 3118069 (8.70 mm/year) in the INT1 season. In SWM season, half of the stations experienced positive trends. However, only the station 2719001 experienced a significant positive trend. In contrast, most of the trends during the INT2 (53\%) season were negative. In the INT2 season, precipitation trend analysis revealed a significant positive trend at the station 44301 (6.10 mm/year) and a significant negative trend was seen at the station 2615131 ( $-6.42 \mathrm{~mm} /$ year $)$. The results of the annual and seasonal trends showed that there is a strong relationship between the INT1 season and the annual data series in the study period. It should be noted that in the study area, the highest amount of rainfall happens during two inter-monsoon seasons.

Since the present study was limited to detect rainfall trends using the MK, Sen's slope estimator and linear regression analysis at the Langat River Basin for the period 1982-2011, it is recommended to utilize other methods such as Spearman's rank correlation, Sen's T-test, moving average methods, etc. In addition, analyzing the trends of extreme climatic variables could also be considered in order to study the hydro-climatic condition of the basin in more detail.

\section{Acknowledgements}

The authors would like to thank the Ministry of Science, Technology and Innovation (MOSTI) for the financial support given for the research project entitled 'Modeling Water Resources and Storm Water Management Strategies for Large Scale Dual-Function Rainwater Tanks Incorporating Climate Change and Urbanization Scenarios'. The authors would also like to express their appreciations to the Hydrology Division, Department of Irrigation and Drainage (DID) at Ampang, Selangor and the Malaysian Meteorology Department (MMD) at Petaling Jaya, both under the Ministry of Natural Resources and Environment (NRE) for the provision of the climatic data.

\section{References}

Andreo B, Jiménez P, Durán J J, Carrasco F, Vadillo I and Mangin A 2006 Climatic and hydrological variations during the last 117-166 years in the south of the Iberian peninsula, from spectral and correlation analyses and continuous wavelet analyses; J. Hydrol. 324 24-39, doi: 10.1016/j.jhydrol.2005.09.010.

Basistha Ashoke, Arya D S and Goel N K 2009 Analysis of historical changes in rainfall in the Indian Himalayas; Int. J. Climatol. 29 555-572, doi: 10.1002/joc.1706.

Bhardwaj R S 2009 Business Statistics; Excel Books.

Birsan Marius Victor, Peter Molnar, Paolo Burlando and Martin Pfaundler 2005 Streamflow trends in Switzerland; J. Hydrol. 314 312-329, doi: 10.1016/j.jhydrol.2005.06. 008.

Bonaccorso B, Cancelliere A and Rossi G et al. 2005 Detecting trends of extreme rainfall series in Sicily; Adv. Geosci. 2 7-11.

Buishand T A and Kempen G T 1988 Trend and seasonal variation of precipitation chemistry data in the Netherlands; Atmos. Environ. 22 339-348.

Caloiero Tommaso, Roberto Coscarelli, Ferrari Ennio and Mancini Marco 2011 Trend detection of annual and seasonal rainfall in Calabria (southern Italy); Int. J. Climatol. 31 44-56, doi: 10.1002/joc.2055.

Cannarozzo M, Noto L V and Viola F 2006 Spatial distribution of rainfall trends in Sicily (1921-2000); Physics and Chemistry of the Earth, Parts A/B/C 31 1201-1211, doi: 10.1016/j.pce.2006.03.022.

Chaouche Keltoum, Luc Neppel, Claudine Dieulin, Nicolas Pujol, Bernard Ladouche, Eric Martin, Dallas Salas and Yvan Caballero 2010 Analyses of precipitation, temperature and evapotranspiration in a French Mediterranean region in the context of climate change; Compt. Rendus Geosci. 342 234-243.

Cheung W H, Senay G B and Singh Ashbindu 2008 Trends and spatial distribution of annual and seasonal rainfall in Ethiopia; Int. J. Atmos. Environ. 13 1723-1734, doi: 10.1002/joc.

Corder G W and Foreman D I 2009 Nonparametric statistics for non-statisticians: A step-by-step approach; Wiley.

Cunderlik J M and Burn D H 2004 Linkages between regional trends in monthly maximum flows and selected climatic variables; J. Hydrol. Eng. 9 246-256.

De Lima M I P, Carvalho S C P and de Lima J L M P 2010 Investigating annual and monthly trends 
in precipitation structure: An overview across Portugal; Nat. Hazards Earth Syst. Sci. 10 2429-2440, doi: 10.5194/nhess-10-2429-2010.

Department of Irrigation and Drainage Malaysia 2012 Hydrological data: Rainfall records for west Malaysia 1970-2012 [Data file]. Water Resources Management and Hydrology Division.

Hamed K H and Ramachandra Rao A 1998 A modified Mann-Kendall trend test for autocorrelated data; J. Hydrol. 204 182-196, doi: 10.1016/S0022-1694(97)00125-X.

Helsel D R and Hirsch R M 1992 Statistical Methods in Water Resources; Studies in Environmental Science, Amsterdam, Elsevier.

Hirsch Robert M, James R Slack and Richard A Smith 1982 Techniques of trend analysis for monthly water quality data; Water Resour. Res. 18 107-121, doi: 10.1029/ WR018i001p00107.

Huang Yilong, Yanglin Wang and Liping Zhang 2008 Long-term trend of chemical composition of wet atmospheric precipitation during 1986-2006 at Shenzhen City, China; Atmos. Environ. 42 3740-3750, doi: 10.1016/ j.atmosenv.2007.12.063.

Jiang Tong, Buda Su and Heike Hartmann 2007 Temporal and spatial trends of precipitation and river flow in the Yangtze River Basin, 1961-2000; Geomorphology 85 143154, doi: 10.1016/j.geomorph.2006.03.015.

Kang Shujiang and Henry Lin 2007 Wavelet analysis of hydrological and water quality signals in an agricultural watershed; J. Hydrol. 338 1-14, doi: 10.1016/j.jhydrol. 2007.01.047.

Kumar Sanjiv, Venkatesh Merwade, Jonghun Kam and Kensey Thurner 2009 Streamflow trends in Indiana: Effects of long term persistence, precipitation and subsurface drains; J. Hydrol. 374 171-183, doi: 10.1016/ j.jhydrol.2009.06.012.

Kundzewicz Zbigniew W and Alice J Robson 2004 Change detection in hydrological records - a review of the methodology/Revue méthodologique de la détection de changements dans les chroniques hydrologiques; Hydrol. Sci. J. 49 7-19.

Malaysia Meteorological Department 2012 Rainfall records for Selangor State Malaysia, 1970-2012.

Miao L, Jun X and Meng Dejuan 2012 Long-term trend analysis of seasonal precipitation for Beijing, China; J. Resourc. Ecol. 3 64-72, doi: 10.5814/j.issn.1674-764x. 2012.01.010.

Modarres Reza, Vicente de Paulo and Rodrigues da Silva 2007 Rainfall trends in arid and semi-arid regions of Iran; J. Arid Environ. 70 344-355, doi: 10.1016/j.jaridenv. 2006.12.024.
Novotny Eric V and Heinz G Stefan 2007 Stream flow in Minnesota: Indicator of climate change; J. Hydrol. 334 319-333, doi: 10.1016/j.jhydrol.2006.10.011.

Oguntunde Philip G, Babatunde J Abiodun and Gunnar Lischeid 2011 Rainfall trends in Nigeria, 1901-2000; J. Hydrol. 411 207-218, doi: 10.1016/j.jhydrol.2011.09. 037.

Olofintoye Oluwatosin, Josiah Adeyemo and Fred Otieno 2012 Impact of Regional Climate Change on Freshwater Resources and Operation of the Vanderkloof Dam System in South Africa; Global Warming - Impacts and Future Perspective, $165 \mathrm{p}$.

Partal Turgay and Ercan Kahya 2006 Trend analysis in Turkish precipitation data; Hydrol. Process. 20 20112026, doi: 10.1002/hyp.5993.

Rana Arun, Cintia Bertacchi Uvo, Lars Bengtsson and Parth Sarthi P 2011 Trend analysis for rainfall in Delhi and Mumbai, India; Climate Dyn. 38 45-56, doi: 10.1007/s00382-011-1083-4.

Razali Nornadiah Mohd and Yap Bee Wah 2011 Power comparisons of shapiro-wilk, kolmogorov-smirnov, lilliefors and anderson-darling tests; J. Statistical Modeling and Analytics 2 21-33.

Serrano A, Mateos V L and Garcia J A 1999 Trend analysis of monthly precipitation over the Iberian peninsula for the period 1921-1995; Phys. Chem. Earth, Part B: Hydrology, Oceans and Atmosphere 24 85-90.

Suhaila J, Deni S M, Zin W Z W and Jemain A A 2010 Trends in peninsular Malaysia rainfall data during the southwest monsoon and northeast monsoon seasons: 1975-2004; Sains Malaysiana 39 533542.

Tabari Hossein and Parisa Hosseinzadeh Talaee 2011 Temporal variability of precipitation over Iran: 1966-2005; J. Hydrol. 396 313-320, doi: 10.1016/j.jhydrol.2010.11.034.

Tabari Hossein and Safar Marofi 2010 Changes of pan evaporation in the west of Iran; Water Resour. Manag. 25 97111, doi: 10.1007/s11269-010-9689-6.

Tangang F T, Juneng L and Ahmad S 2006 Trend and interannual variability of temperature in Malaysia: 1961-2002; Theoret. Appl. Climatol. 89 127-141, doi: $10.1007 / \mathrm{s} 00704-006-0263-3$.

Wu C L, Chau K W and Li Y S 2009 Predicting monthly streamflow using data-driven models coupled with datapreprocessing techniques; Water Resour. Res. 45, Wiley Online Library.

Zhang Xuebin, Lucie A Vincent, Hogg W D and Ain Niitsoo 2000 Temperature and precipitation trends in Canada during the 20th century; Atmosphere-Ocean 38 395-429, doi: 10.1080/07055900.2000.9649654. 